\title{
Repair of anomalous origin of the left coronary artery from the pulmonary artery in infants
}

\author{
Piotr A. Kazmierczak ${ }^{a, *}$, Katarzyna Ostrowska ${ }^{b}$, Pawel Dryzek ${ }^{b}$, Jadwiga A. Moll ${ }^{b}$ and Jacek J. Moll \\ a Department of Cardiosurgery, Polish Mother's Memorial Hospital-Research Institute, Lodz, Poland \\ b Department of Cardiology, Polish Mother's Memorial Hospital-Research Institute, Lodz, Poland \\ * Corresponding author. Department of Cardiosurgery, Polish Mother's Memorial Hospital-Research Institute, 281/289 Rzgowska St., 93-338 Lodz, Poland. \\ Tel: +48-42-2712012; fax: +48-42-2711454; e-mail: kazmierczak_piotr@yahoo.com (P.A. Kazmierczak).
}

Received 5 November 2012; received in revised form 24 January 2013; accepted 27 January 2013

\begin{abstract}
OBJECTIVES: Anatomical repair seems an ideal method for the surgical treatment of the anomalous left coronary artery arising from the pulmonary artery (ALCAPA) in infancy. The medium-term outcome has been investigated for infants with ALCAPA following the restoration of a dual-coronary arterial circulation.
\end{abstract}

METHODS: Between April 1995 and July 2012, 23 infants with a median age of 4 months underwent surgical repair of ALCAPA in our department. Direct implantation of the anomalous coronary artery into the ascending aorta was feasible in 16 patients. A trap door flap method was used in 5 cases and a tubular extension technique in 2. No infant underwent mitral valve repair at the time of ALCAPA surgery. Left ventricular function and the degree of mitral valve regurgitation were assessed during a 10-year follow-up.

RESULTS: Four patients died in the early postoperative period, without independent predictors associated with this mortality. During follow-up, improvement in myocardial function occurred in all patients both early and late. There was only one improvement in severe mitral valve regurgitation. Subsequently, 2 children needed mitral valve replacement. There were no early or late reoperations of the reimplanted coronary arteries.

CONCLUSIONS: Aortic reimplantation is an effective surgical treatment for ALCAPA in infants burdened with a low risk of reoperation due to coronary artery stenosis. There was good potential for myocardial recovery within the first year after surgery. Restoration of the anatomical coronary circulation did not improve mitral valve function in infants with severe preoperative mitral incompetence.

Keywords: Congenital heart disease $\cdot$ Coronary artery anomaly $\cdot$ Mitral valve regurgitation $\cdot$ Infant

\section{INTRODUCTION}

Anomalous left coronary artery arising from the pulmonary artery (ALCAPA) is one of the few congenital heart anomalies in which myocardial function is profoundly compromised, with a clinical spectrum described in 1933 by Bland et al. [1] Myocardial ischaemia develops at the territory of the left coronary artery, interfering with left ventricular contractility and mitral valve function. The onset of the symptoms and the degree of myocardial insufficiency, or mitral valve regurgitation, depend on a balance of the rapidity of ductus arteriosus closure, maintenance of pulmonary hypertension and development of intercoronary collateral vessels from the right coronary artery to the ALCAPA The early onset of symptoms-days to months after birth-can develop in patients with little or no intercoronary collateral vessels [2]. If the collaterals are well developed, the symptoms may be noticed in adulthood, or sometimes never appear [3].

Re-establishment of a dual-coronary system seems to be an ideal method for the surgical treatment of ALCAPA in infancy $[4,5]$. Since 1995, direct implantation of the ALCAPA into the ascending aorta or its modifications has become our method of choice for treatment.

\section{MATERIALS AND METHODS}

Between April 1995 and July 2012, 23 infants underwent surgical treatment for ALCAPA at the Department of Pediatric Cardiac Surgery of Polish Mother's Memorial Hospital-Research Institute, Lodz, Poland. There were 16 females and 7 males. Median age of the patients was 4 (range 2-12 months). Eighteen infants were younger than 6 months, and 7 of them were younger than 3 months. Median weight of the patients was 5.2 (range $3.5-8.1 \mathrm{~kg}$ ). The preoperative diagnosis was established by two-dimensional transthoracic echocardiography (TTE). Fourteen patients underwent coronary angiography that confirmed ambiguous diagnoses. The left coronary artery origin was found on the main pulmonary trunk in 21 infants and on the right pulmonary artery in 2. Associated anomalies were seen in 2 infants: one was diagnosed with a ventricular septal defect (VSD) and patent ductus arteriosus (PDA), and one with PDA. Fifteen infants presented symptoms of severe left ventricular dysfunction and congestive heart failure. Inotropes were administered in 14 of them (dobutamine in 10 and dopamine in 4 infants). Myocardial infarction was electrocardiographically confirmed in 2 patients. Cardiac arrest was presented in 1 child. Preoperative mechanical 
ventilation was used in 3 infants because of cardiopulmonary instability.

\section{Cardiac function}

All infants underwent detailed clinical examinations and complete TTEs at the time of diagnosis, at home discharge and at postoperative follow-up time-points (1, 5 and 10 years after the surgery). Left ventricular function was measured by left ventricular shortening fraction (LVSF), left ventricular ejection fraction (LVEF), left ventricular end-diastolic diameter (LVEDD) and left ventricular end-diastolic volume (LVEDV). LVEDD and LVEDV were indexed to normal values for body surface area for the comparison of different age groups. Mitral valve regurgitation (MR) was evaluated by color Doppler TTE and classified as none, mild, moderate or severe. The preoperative degree of the MR was none in 2, mild in 3, moderate in 13 and severe in 5 infants. LVEF was severely impaired $(\leq 30 \%)$ in 9 patients, impaired $(31-40 \%)$ in 6 , mildly impaired (41-50\%) in 1 and normal $(\geq 51 \%)$ in 7 .

\section{Surgical technique}

All patients were approached through median sternotomy. High aortic and bicaval venous cannulations were used, and moderate hypothermia was established on cardiopulmonary bypass circulation (CPB). An aortic cross-clamp was placed high, and $20 \mathrm{ml} / \mathrm{kg}$ of cold-blood cardioplegia solution was infused into the aortic root while simultaneously occluding the main pulmonary artery or its branches individually. A transverse incision in the pulmonary trunk was made above the level of the coronary origin, and $10 \mathrm{ml} / \mathrm{kg}$ of cardioplegia was infused directly to the ALCAPA. The coronary orifice was excised with a generous cuff of the pulmonary sinus wall, and the proximal portion of the coronary artery was mobilized. A simple hole in the ascending aorta was created, and the left coronary artery was directly reimplanted to the aortic wall in 16 patients. To avoid excessive tension on a reimplanted coronary artery, a 'trap-door' technique of aortic incision was used in 5 cases to create medially, laterally or caudally-based flaps for ALCAPA reimplantation. In 2 patients, the distance between the ALCAPA and the aorta was too long for direct implantation, and a tubular extension technique was used to avoid excessive tension on a reimplanted coronary artery, as described by others [6, 7]. Briefly, the isolated segment of the pulmonary artery containing the origin of the ALCAPA was folded with the orifice of the coronary artery as its fulcrum, and its side edges sutured to each other to form an extension tube of tissue to lengthen the coronary artery. This extrapulmonary autologous tension-free tube was implanted into the wall of the ascending aorta.

After the left coronary artery was transferred, the cross-clamp was removed. The defect in the main pulmonary artery or the right pulmonary artery was filled with an autologous native pericardium. The procedure was completed with reanastomosis of the pulmonary artery. CPB was stopped in normothermic conditions after a reperfusion period.

PDA ligation and VSD closure were additionally performed in patients with associated anomalies. There was no concomitant mitral valve surgery, regardless of the severity of MR.

CPB time ranged from 63 to 193 min (median 81), and aortic cross-clamp time ranged from 19 to $46 \mathrm{~min}$ (median 26). One patient required deep hypothermia. Mechanical circulatory support was not used in any case. Delayed sternal closure was done in 3 patients because of haemodynamic instability that developed after temporary sternal closure. All patients were managed with infusions of inotropes. Dobutamine was the standard catecholamine used in 15 patients. Dopamine and milrinone were administered to 5 infants with good left ventricular contractility. Adrenaline was required in 3 patients with low cardiac output and the symptoms of cardiac shock.

\section{Data collection and statistical analysis}

Clinical and operative data of all the patients were retrospectively analyzed. For all the quantitative parameters, a mean with a standard deviation $( \pm \mathrm{SD})$ or a median $(\mathrm{Me})$ were measured. The statistical significance of differences was estimated by the analysis of variance (ANOVA) or the Kruskal-Wallis tests (when departing from normality) and the post hoc multiple comparisons using the Student-Newman-Keuls test (or the non-parametric Dunn's multiple comparison test). A paired Student's $t$-test was applied to compare preoperative values with early postoperative data (for all data not departing from normality).

Continuous variables, assessed as possible predictors of death, were sought in logistic regression analysis. Dichotomous variables were analyzed by the Fisher's exact test. These risk factors included preoperative explanatory variables: age, weight, severity of MR, LVEDD, LVEDV, LVEF, LVSF, mechanical ventilation, inotrope intake and the presence of associated diagnoses (e.g. other congenital heart defects, myocarditis, myocardial infarction, cardiac arrest). A $P$-value $<0.05$ was considered statistically significant.

\section{RESULTS}

\section{Mortality}

Four patients died in the early postoperative period (from $10 \mathrm{~h}$ to 12 days postoperatively). The non-survivors presented symptoms of severe cardiac failure preoperatively (Table 1). Sepsis developed in the first of them, the infant dying on Day 12 with symptoms of multiorgan failure. In the second infant, the symptoms of severe left ventricular failure occurred in the early postoperative period and death occurred 6 days after the surgery. Attempts at weaning from CPB were unsuccessful in the third death (operated on with the tubular extension technique) after $10 \mathrm{~h}$ of CPB and maximal inotropic support. Persistent ventricular arrhythmias and low cardiac output occurred in the last patient, who died several hours after the surgery. Apart from ALCAPA, this infant was preoperatively diagnosed with Coxsackie viral myocarditis. Autopsy showed diffused interstitial myocarditis with a dominance of lymphoid cells, indicating complete suppression of the inflammatory process. Additionally, there was multifocal fibrosis and scarring in the myocardium, including the papillary muscles, and the left ventricle was markedly enlarged. No other patient died in the registered follow-up. There were no independent predictors associated with postoperative mortality.

\section{Early postoperative period and follow-up}

Except for 1 patient, who was extubated 52 days postoperatively and spent 57 days in the intensive care unit (ICU), the median 
Table 1: Preoperative clinical profile of infants non-surviving in the early postoperative period

\begin{tabular}{|c|c|c|c|c|c|c|c|c|c|c|c|c|}
\hline $\begin{array}{l}\text { Year of } \\
\text { operation }\end{array}$ & Sex & $\begin{array}{l}\text { Age } \\
\text { (months) }\end{array}$ & $\begin{array}{l}\text { Weight } \\
(\mathrm{kg})\end{array}$ & MR & $\begin{array}{l}\text { LVSF } \\
(\%)\end{array}$ & $\begin{array}{l}\text { LVEF } \\
(\%)\end{array}$ & $\begin{array}{l}\text { LVEDD } \\
(\mathrm{mm})\end{array}$ & $\begin{array}{l}\text { LVEDD } \\
\text { indexed to } \\
\text { normal }\end{array}$ & $\begin{array}{l}\text { LVEDV } \\
(\mathrm{ml})\end{array}$ & $\begin{array}{l}\text { LVEDV } \\
\text { indexed to } \\
\text { normal }\end{array}$ & Inotrops & Others \\
\hline 1998 & $\mathrm{~F}$ & 3 & 6.2 & Moderate & 11 & 24.5 & 37.3 & 1.13 & 51 & 3.30 & Dobutamine & $\begin{array}{l}\text { Mechanical } \\
\text { ventilation }\end{array}$ \\
\hline 1999 & $\mathrm{~F}$ & 2 & 3.5 & Moderate & 18.8 & 39.2 & 40 & 1.64 & 72 & 5.54 & Dobutamine & VSD, PDA \\
\hline 2000 & $\mathrm{~F}$ & 4 & 4.8 & Severe & 13.5 & 28.7 & 45 & 1.50 & 92.4 & 7.11 & Dobutamine & $\begin{array}{l}\text { Myocardial } \\
\text { infarction }\end{array}$ \\
\hline 2012 & M & 4 & 4.7 & Moderate & 19 & 40 & 35.5 & 1.18 & 52 & 4.00 & Dopamine & $\begin{array}{l}\text { Myocardial } \\
\text { infarction, } \\
\text { myocarditis, } \\
\text { cardiac arrest }\end{array}$ \\
\hline
\end{tabular}

F: female; M: male; LVEDD: left ventricular end-diastolic diameter; LVEDV: left ventricular end-diastolic volume; LVEF: left ventricular ejection fraction; LVSF: left ventricular shortening fraction; MR: mitral valve regurgitation; PDA: patent ductus arteriosus; VSD: ventricular septal defect.
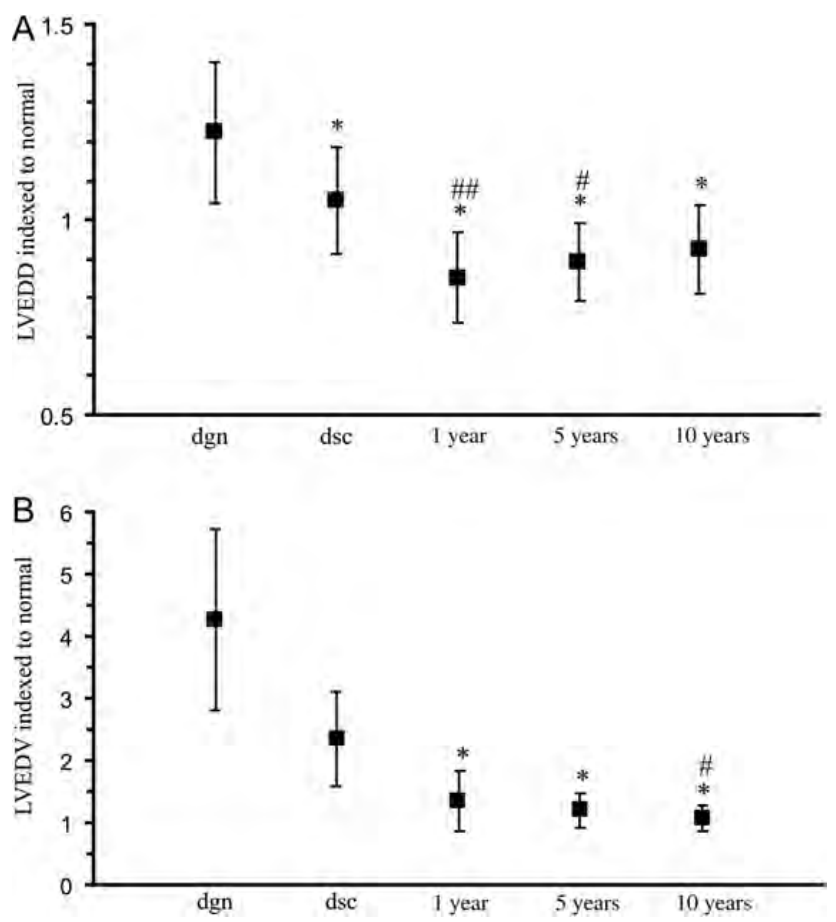

Figure 1: Longitudinal assessment of (A) left ventricular end-diastolic diameter (LVEDD) and (B) left ventricular end-diastolic volume (LVEDV) before and after repair of the anomalous left coronary artery from the pulmonary artery. LVEDD and LVEDV are indexed to normal values for body surface area. dgn: at the time of diagnosis; dsc: at the time of home discharge. Significance of differences for LVEDD was estimated by ANOVA and the post hoc multiple comparisons using Student-Newman-Keul's test. Significance of differences for LVEDV was estimated by the non-parametric Kruskal-Wallis test and the post hoc multiple comparisons by the Dunn's test. ${ }^{*} P<0.001$ vs dgn, ${ }^{\#} P<0.05$ vs dsc, ${ }^{\# \#} P<0.01$ vs dsc.

time to extubation was 46 (range 6-380 h), time to discharge from the ICU was 5 (range 1-25 days) and total postoperative stay in the hospital was 15 (range 7-36 days). TTE demonstrated antegrade flow in the new coronary artery system in all children. Mean postoperative LVSF was $28.9 \pm 13.5 \%$, which was significantly improved compared with $19.3 \pm 10.7 \%$ preoperatively $(P<0.02)$. Mean LVEF also increased postoperatively $(54.1 \pm 20.3$ vs $40.3 \pm 20.0 \%$ before operation; $P<0.04$ ). Significant reductions
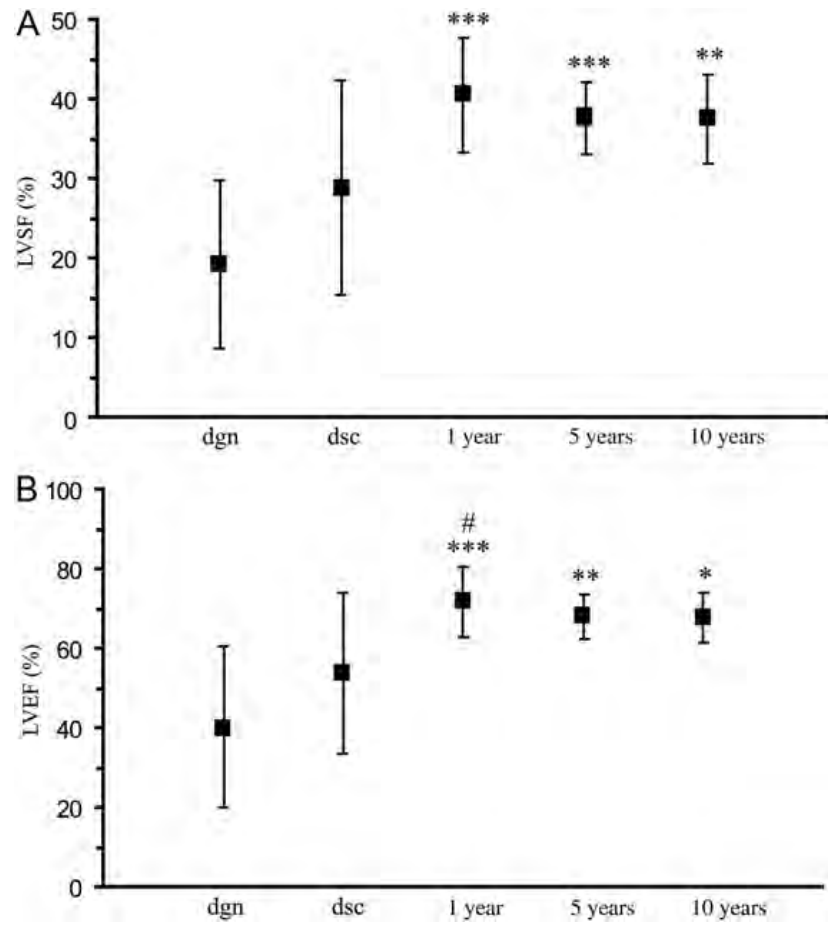

Figure 2: Longitudinal assessment of (A) left ventricular shortening fraction (LVSF) and (B) left ventricular ejection fraction (LVEF) before and after repair of the anomalous left coronary artery from the pulmonary artery. dgn: at the time of diagnosis; dsc: at the time of home discharge. Significance of differences was estimated by the non-parametric Kruskal-Wallis test and the post hoc multiple comparisons by the Dunn's test. ${ }^{*} P<0.05$ vs dgn, ${ }^{* *} P<0.01$ vs dgn, ${ }^{* * *} P<0.001$ vs dgn, ${ }^{\#} P<0.05$ vs dsc.

in LVEDV (36.4 \pm 13.3 vs $63.7 \pm 19.7 \mathrm{ml}$ preoperatively; $P<0.0001$ ) and LVEDD $(32.9 \pm 5.2$ vs $37.7 \pm 4.5 \mathrm{~mm}$ preoperatively; $P<0.004)$ were also reported.

Among the 19 operated-on survivors, follow-up was registered in 15 patients. Time since surgery of the 4 other children was $<1$ year. Left ventricular function gradually improved at follow-up (Figs. 1 and 2).

Standard and Holter electrocardiography showed mild ventricular arrhythmias in 4 patients. Pharmacological treatment was not required in any of them. 
During follow-up, myocardial perfusion scintigraphy with technetium-99m as radionuclide was performed in 8 children. Perfusion deficits of the anterior or anterior-lateral segments were observed at rest in 6 of them, but also during a dobutamine stress test in one other patient. No deterioration of perfusion was seen on exertion in any patients.

Cardiac catheterization was done in 2 children (aged 5 and 9 years) with complaints of atypical chest pain, and with myocardial perfusion impairment in scintigraphy and dobutamine stress tests. There was normal flow across the transferred left coronary artery in the investigated patients, and there were no reoperations of the reimplanted coronary arteries.

In 1 patient, postoperative moderate pulmonary stenosis was observed, which reduced to a mild condition 1 year after the operation of ALCAPA. Aortic valve function was normal in all patients.

\section{Mitral valve}

One infant with severe preoperative mitral incompetence died in the early postoperative period (Table 1). There was only one improvement in severe MR (Fig. 3). Two children were reoperated on because of severe postoperative MR. Mitral valvuloplasties were performed on both at the second operation (at 8 and 10 months after primary procedure); and finally, mitral valve replacements were applied. St. Jude mechanical mitral valve (diameter of $23 \mathrm{~mm}$ ) was implanted in the first of them 3 years after ALCAPA operation, and a ATS Medical mechanical mitral valve of $21 \mathrm{~mm}$ diameter (ATS Medical, Inc, Minneapolis, MN) was implanted in the second child 2 years after primary surgery. Moderate MR was observed in 3 of 13 patients who completed a 5-year follow-up, and in only 1 patient who completed a 10-year follow-up of 9 patients. None or mild MR was noted in the others at these timepoints (Fig. 3). An increase in MR was found in 4 patients: from none to mild in 1, from mild to moderate in 2 and from moderate to severe in 1 . In the last of these patients, mitral functioning was back to moderate in a 5-year follow-up, which remained moderate 10 years after the operation.

\section{DISCUSSION}

Patients with ALCAPA have been operated on in our department since 1992. The operation of Takeuchi et al. [8] had been the method of surgical treatment for the first 3 years, but was abandoned in 1995 because of unsatisfactory postoperative recovery and later complications (data not published). Since 1995, we have performed 28 coronary reimplantations of the ALCAPA, 23 of them in infants. We chose infants in this study as it guaranteed the homogeneity of patients because: (i) coronary collaterals were insufficiently developed to maintain myocardial perfusion, (ii) they presented more or less severe symptoms of heart failure preoperatively and (iii) they urgently required surgical treatment after diagnosis. Direct aortic reimplantation has progressively evolved as the technique of choice in most centers $[5,9]$. Since the first report of Neches et al. [10], this procedure has been successfully used in infants and adults. The operation has a low mortality index and a high rate of anastomotic patency; it usually brings about a dramatic improvement in the left ventricular function [11-14].

Four patients died early after surgery. The survival rate was comparable to the results from other centers and acceptable

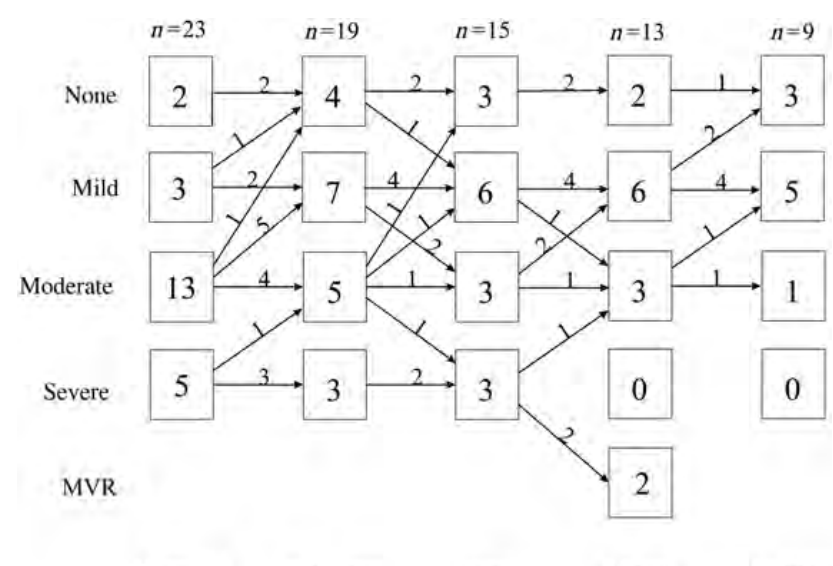

Figure 3: Mitral valve regurgitation before (diagnosis) and after (discharge, 1, 5 and 10 years) repair of the anomalous left coronary artery from the pulmonary artery with the corresponding number of patients at risk (in squares). Numbers of patients passing to the next follow-up interval are presented above the arrows. MVR: mitral valve replacement.

in the population of infants [12-16]. Ando et al. [17] did not report any deaths during a median follow-up of 36 months, but their group was small (13 patients) with a median age of 3.9 years. There were also no deaths in Muneer's group [18]. Admirable results were presented by Alexi-Meskishvili et al. [11], who reported no deaths both in early and later postoperative periods, and most of their patients were also infants. They used a temporary left ventricular assist device (LVAD) in 6 infants and, therefore, a Berlin Heart Excor pneumatic VAD in 2 patients, whose functional recovery of the left ventricle was insufficient. We did not use LVAD or extracorporeal membrane oxygenation (ECMO) in any of our infants. Three patients died before 2000, when our ECMO programme began and we did not have LVADs. The condition of the infant operated on in 2012 was stable in the early postoperative period, but it deteriorated several hours after the surgery, and circulatory resuscitation was unsuccessful.

There was no statistical correlation between mortality and preoperative factors, probably because of the homogeneity of the patients of comparable age, weight and poor preoperative condition, or because of the relatively small group of patients. Preoperative age and LVEF $<30 \%$ were predictive for 30 -day mortality in the data of Lange et al. [13]. Poor LVEF was also an incremental risk factor for early mortality in the patients of Ben Ali et al. [19]. Schwartz et al. [20] suggested severe preoperative MR as a risk factor of death after ALCAPA surgery. All infants dying in our population had also significant (severe or moderate) preoperative mitral valve regurgitation, but this correlation was not statistically significant in our small sample of patients.

Progress of myocardial contractility after surgery was noticeable in our patients. There was good potential for myocardial recovery within the first year after direct aortic reimplantation of ALCAPA. This demonstrates the reversibility of ischaemic processes in the cardiac myocytes. Left ventricular function remained constant at subsequent intervals. Despite restoration of global myocardial function, perfusion scintigraphy and dobutamine stress tests showed perfusion impairments of anterior or anterior-lateral segments of the left ventricle late after ALCAPA repair. Perfusion regional deficit is related to left ventricular wall scar tissue and can potentially serve as a substrate for cardiac arrhythmia later in life [11]. 
None of the infants operated on developed stenosis or occlusion of the reimplanted coronary arteries reported in infants by other authors $[12,19]$.

\section{Mitral valve}

MR very commonly presents, often revealed as a first symptom of ALCAPA [21]. The pathophysiology of MR in ALCAPA is the combination of papillary muscles dysfunction, left ventricular dyskinesis, left ventricular dilatation and mitral annulus enlargement. Mitral valvuloplasty during ALCAPA surgery remains controversial. Isomatsu et al. [22] recommended that simultaneous mitral annuloplasty be performed at the time of ALCAPA operation in all patients with mild to severe MR. Contrarily, Caspi et al. [23] saw regression of MR in patients with ALCAPA without mitral valve repair. Alsoufi et al. [12] noticed mitral improvement both in patients with mitral valvuloplasty and without mitral surgery. We did not carry out mitral repair in any of our patients. Our strategy was based on the idea that the reversal of left ventricular dilatation, and papillary dyskinesis with coronary revascularization could improve valve function. We expected that ischaemia, rather than necrosis, was responsible for left ventricular and mitral valve dysfunction, and this process would have been reversible. This decision was correct for all infants, but not for those with severe MR. Only improvement in mitral valve function in one of the patients with the severest MR gives evidence of irreversible necrotic myocardial damage or papillary muscle infarction. The probable mechanism of progressive mitral failure was of long-term MR, leading to mitral annulus dilatation, with mitral incompetence being exacerbated such that later reoperations on mitral valve were insufficient. Alexi-Meskishvili et al. [11] performed mitral repair in patients with severe MR with excellent postoperative results. Alsoufi et al. [12] recommended concomitant mitral valve repair in patients with severe MR or in whom preoperative echocardiographic assessment of valve dysfunction showed a possible organic rather than functional pathology. We agree with Alexi-Meskishvili and Alsoufi. Our current approach is to perform concomitant mitral valve annuloplasty in infants with the severest MR during ALCAPA repair.

\section{Conflict of interest: none declared.}

\section{REFERENCES}

[1] Bland EF, White PD, Garland J. Congenital anomalies of the coronary arteries: report of an unusual case associated with cardiac hypertrophy. Am Heart J 1933;8:787-801.

[2] Rein AJ, Colan SD, Parness IA, Sanders SP. Regional and global left ventricular function in infants with anomalous origin of the left coronary artery from the pulmonary trunk: preoperative and postoperative assessment. Circulation 1987;75:115-23.

[3] Yau JM, Singh R, Halpern EJ, Fischman D. Anomalous origin of the left coronary artery from the pulmonary artery in adults: a comprehensive review of 151 adult cases and a new diagnosis in a 53-year-old woman Clin Cardiol 2011;34:204-10.
[4] Dodge-Khatami A, Mavroudis C, Backer CL. Anomalous origin of the left coronary artery from the pulmonary artery: collective review of surgical therapy. Ann Thorac Surg 2002;74:946-55.

[5] Moraes F, Lincoln C. Anomalous origin of left coronary artery. Evolution of surgical treatment. Eur J Cardiothorac Surg 1996;10:603-8.

[6] Barth MJ, Allen BS, Gulecyuz M, Chiemmongkoltip P, Cuneo B, Ilbawi $\mathrm{MN}$. Experience with an alternative technique for the management of anomalous left coronary artery from the pulmonary artery. Ann Thorac Surg 2003;76:1429-34.

[7] Turley K, Szarnicki RJ, Flachsbart KD, Richter RC, Popper RW, Tarnoff H. Aortic implantation is possible in all cases of anomalous origin of the left coronary artery from the pulmonary artery. Ann Thorac Surg 1995; 60:84-9.

[8] Takeuchi S, Imamura H, Katsumoto K, Hayashi I, Katohgi T, Yozu R et al. New surgical method for repair of anomalous left coronary artery from pulmonary artery. J Thorac Cardiovasc Surg 1979;78:7-11.

[9] Vouhe PR, Tamisier D, Sidi D, Vernant F, Mauriat P, Pouard P et al. Anomalous left coronary artery from the pulmonary artery: results of isolated aortic reimplantation. Ann Thorac Surg 1992;54:621-6.

[10] Neches WH, Mathews RA, Park SC, Lenox CC, Zuberbuhler JR, Siewers $\mathrm{RD}$ et al. Anomalous origin of the left coronary artery from the pulmonary artery. A new method of surgical repair. Circulation 1974;50:582-7.

[11] Alexi-Meskishvili V, Nasseri BA, Nordmeyer S, Schmitt B, Weng YG, Bottcher W et al. Repair of anomalous origin of the left coronary artery from the pulmonary artery in infants and children. J Thorac Cardiovasc Surg 2011;142:868-74.

[12] Alsoufi B, Sallehuddin A, Bulbul Z, Joufan M, Khouqeer F, Canver CC et al. Surgical strategy to establish a dual-coronary system for the management of anomalous left coronary artery origin from the pulmonary artery. Ann Thorac Surg 2008;86:170-6.

[13] Lange R, Vogt M, Horer J, Cleuziou J, Menzel A, Holper $\mathrm{K}$ et al. Long-term results of repair of anomalous origin of the left coronary artery from the pulmonary artery. Ann Thorac Surg 2007;83:1463-71.

[14] Michielon G, Di Carlo D, Brancaccio G, Guccione P, Mazzera E, Toscano A et al. Anomalous coronary artery origin from the pulmonary artery: correlation between surgical timing and left ventricular function recovery. Ann Thorac Surg 2003;76:581-8.

[15] Brown JW, Ruzmetov M, Parent JJ, Rodefeld MD, Turrentine MW. Does the degree of preoperative mitral regurgitation predict survival or the need for mitral valve repair or replacement in patients with anomalous origin of the left coronary artery from the pulmonary artery? J Thorac Cardiovasc Surg 2008;136:743-8.

[16] Ojala T, Salminen J, Happonen JM, Pihkala J, Jokinen E, Sairanen H. Excellent functional result in children after correction of anomalous origin of left coronary artery from the pulmonary artery-a populationbased complete follow-up study. Interact CardioVasc Thorac Surg 2010; 10:70-5.

[17] Ando M, Mee RB, Duncan BW, Drummond-Webb JJ, Seshadri SG, Igor Mesia C. Creation of a dual-coronary system for anomalous origin of the left coronary artery from the pulmonary artery utilizing the trapdoor flap method. Eur J Cardiothorac Surg 2002;22:576-81.

[18] Muneer AM, Rostron AJ, Leslie H Jr, Chaudhari MP, Hasan A. Towards an anatomically correct repair for anomalous left coronary artery arising from the pulmonary trunk. Cardiol Young 2008;18:372-8.

[19] Ben Ali W, Metton O, Roubertie F, Pouard P, Sidi D, Raisky O et al. Anomalous origin of the left coronary artery from the pulmonary artery: late results with special attention to the mitral valve. Eur J Cardiothorac Surg 2009;36:244-8.

[20] Schwartz ML, Jonas RA, Colan SD. Anomalous origin of left coronary artery from pulmonary artery: recovery of left ventricular function after dual coronary repair. J Am Coll Cardiol 1997;30:547-53.

[21] Dahle G, Fiane AE, Lindberg HL. ALCAPA, a possible reason for mitral insufficiency and heart failure in young patients. Scand Cardiovasc J 2007; 41:51-8.

[22] Isomatsu Y, Imai Y, Shin'oka T, Aoki M, Iwata Y. Surgical intervention for anomalous origin of the left coronary artery from the pulmonary artery: the Tokyo experience. J Thorac Cardiovasc Surg 2001;121:792-7.

[23] Caspi J, Pettitt TW, Sperrazza C, Mulder T, Stopa A. Reimplantation of anomalous left coronary artery from the pulmonary artery without mitral valve repair. Ann Thorac Surg 2007;84:619-23. 